\title{
İnegöl (Bursa) ve Domaniç (Kütahya) Yöresi Doğu Kayını (Fagus orientalis Lipsky) Ormanları İçin Önemli Bir Tehdit: Kızllkuyruklu Kayın Tırtılı - Calliteara pudibunda (Linneaus, 1758)
}

\author{
Oğuzhan Sarıkaya ${ }^{*}$, Ali İhsan Kadığuları², Özden Açıc ${ }^{3}$ \begin{abstract}
${ }^{2}$ Bursa Teknik Üniversitesi, Orman Fakültesi, Orman Mühendisliği Bölümü, Bursa, Türkiye (ORCID: 0000-0002-3102-6321) ali.kadiogullari@btu.edu.tr ${ }^{3}$ Bursa Orman Bölge Müdürlüğü, Bursa, Türkiye (ORCID: 0000-0003-3159-4828) ozdenacici@ogm.gov.tr
\end{abstract} \\ 1* Bursa Teknik Üniversitesi, Orman Fakültesi, Orman Mühendisliği Bölümü, Bursa, Türkiye (ORCID: 0000-0001-5124-6279) oguzhan.sarikaya@btu.edu.tr
}

(İlk Geliş Tarihi 22 Eylül 2020 ve Kabul Tarihi 9 Ocak 2021)

(DOI: $10.31590 /$ ejosat.798622)

ATIF/REFERENCE: Sarıkaya, O., Kadığulları, A.İ. \& Açıcı, Ö. (2021). İnegöl (Bursa) ve Domaniç (Kütahya) Yöresi Doğu Kayını (Fagus orientalis Lipsky) Ormanları İçin Önemli Bir Tehdit: Kızılkuyruklu Kayın Tırtılı - Calliteara pudibunda (Linneaus, 1758). Avrupa Bilim ve Teknoloji Dergisi, (21), 131-135.

$\ddot{O} \mathbf{z}$

Ülkemiz ormanlarında ciddi ekonomik kayıplara neden olan zararlı böcek türleri arasında Lepidoptera takımına bağlı türler önemli bir yeri tutmaktadır. Özellikle larvalarının beslenmesi sonucunda artım kayıplarına neden olmakta, ağaçları zayıf düşürerek sekonder karakterli zararlılara zemin oluşturabilmektedir. Ülkemiz kayın ormanlarında ekonomik zarara yada epidemiye yol açan zararlı türlerle sıklıkla rastlanılmamakla birlikte son yıllarda Bursa-İnegöl ve Kütahya-Domaniç sınırında yer alan kayın ormanlarında bir lepidoptera türü olan Calliteara pudibunda (Linneaus, 1758) (Lep.: Erebidae, Lymantriinae) önemli zararlarıyla dikkati çekmektedir. Çalışmada, böceğin morfolojisi ve zarar şekli ile gözlemler gerçekleştirilmiş, insansız hava araçlarından dronlara entegre edilen RGM mono kameralar ile zararlının larvalarının etkili olduğu alanlar ve böceğin ilerleme yönü tespit edilmiştir. Zarara uğrayan alanın ortofoto haritaları üzerinden sahada genel durum değerlendirildiğinde sahada, böceğin 2019 yılında zarara neden olduğu alan 453,80 hektar olarak ölçülmüştür. Zararlının mücadelesinde mekanik ve biyolojik savaşı bir arada tercih edileceği entegre savaş yöntemlerinin tercih edilmesi önerilmektedir.

\section{An Important Threat to the Eastern Beech (Fagus orientalis Lipsky) Forests of İnegöl (Bursa) and Domaniç (Kütahya) Region: Pale Tussock Moth - Calliteara pudibunda (Linneaus, 1758)}

\begin{abstract}
The species belonging to the Lepidoptera are among the pest insect species that cause serious economic losses in Turkish forests. Especially as a result of feeding their larvae, it causes incremental losses, weakens the trees and can form a basis for secondary pests. Although harmful species that cause economic damage or epidemic in our country's beech forests are not frequently encountered, Calliteara pudibunda (Linneaus, 1758) (Lep.: Erebidae, Lymantriinae), a lepidoptera species in the beech forests located on the Bursa-İnegöl and Kütahya-Domaniç border, has attracted attention with its important damages. In this study, observations were made with the morphology and damage type of the insect, and the areas where the pest's larvae were effective and the progression direction of the insect were determined with RGM mono cameras integrated into drones from unmanned aerial vehicles. When the general situation in the field is evaluated using the orthophoto maps of the damaged area, the area where the insect caused the damage in 2019 was measured as 453.80 hectares. It is recommended to choose integrated pest management methods in which mechanical and biological control methods will be preferred together in controlling against the pest.
\end{abstract}

Keywords: Calliteara pudibunda, Beech, Morphology, Damage, Distribution. 


\section{Giriş}

Ormanlar, kendine özgü bir ekosistem içinde varlığııı sürdürebilen; topluma sosyal, kültürel ve ekonomik yararlar sağlayan ve aynı zamanda kendini yenileyebilen doğal kaynaklardan en önemlisidir. Özellikle son yüzyıl içinde giderek artan dünya nüfusu ve bunun getirdiği sosyal baskı, çevre kirlenmesi, yangınlar ve böcek zararları gibi birçok olumsuz etmenlerle ormanlar giderek azalmış ve bu durum günümüzde de hızını kaybetmeden devam etmektedir.

Ormanların ekolojik fonksiyonları biyolojik çeşitlilik ile yerine getirilmektedir (Pearce ve Pearce, 2001). Ormanlar, sahip oldukları su ekosistemleri, odun ve odun dişı ürün ve hizmetleri ile sayısız ölçülen ve ölçülemeyen fayda ve fonksiyonlara sahiptir. Aynı zamanda, bu ekosistemler bitki, toprak ve su kaynakları dengesinin, kırsal alandaki sosyal istikrarın, barajların uzun ömürlü olmasının ve gıda güvenliğinin temel sigortasıdır (Konukçu, 2001).

Ormancılığın en önemli prensiplerinden birisi sürekliliğin sağlanmasıdır (Akyol ve Tolunay, 2014). Bunun gerçekleştirilebilmesi her şeyden önce ormanların tekniğine uygun şekilde işletilmesi, bakımlarının yapılarak korunmasına bağlıdır. Orman alanlarını tehdit eden tehlikeleri iyi tanımak ve bunlara karşı yerinde ve zamanında gerekli tedbirleri almak büyük önem taşımaktadır. Böcekler ormanları tehdit eden en önemli faktörlerden birisi olup, ormana zararlı etkilerini ortadan kaldırabilmek veya hiç olmazsa ekonomik zarar düzeyinin altında tutabilmek, ancak onların biyolojisini ve yayılışını iyi bilmek, yerine ve zamanına göre savaş yöntemlerini uygulamakla mümkün olmaktadır (Akyol ve Sarıkaya, 2017).

Ülkemizdeki iklim koşulları ve dolayısıyla bitki tür çeşitliliği ormanlarda yıllarca varlığını hissettiren birçok böceğin yaşamlarını elverişli kılmıştır. Entomolojik kaynaklı zararların ortaya çıkmasında etkili olan iklim faktörleri, konukçu bitkileri strese sokarak daha az dayanıklı hale getirmekte yada zararlı böcek türlerinin üreme potansiyelinde ve popülasyonunda artışa neden olabilmektedir. Nitekim sera gazı emisyonlarının yol açtığı küresel ısınma ve iklim değişikliği Hükümetlerarası İklim Değişikliği Paneli (IPCC)'ne göre, küresel ortalama sicaklık 1880-2012 yılları arasında $0,85^{\circ} \mathrm{C}$ artmıştır (IPCC, 2014). Bu artışın etkileri böcek türlerinin yatay ve dikey dağılışlarının genişlemesi yada epidemi yapma kapasitelerinin artması olarak karşımıza çıkmaktadır (Sarıkaya ve ark., 2018).

Ülkemiz ormanlarında ciddi ekonomik kayıplara neden olan zararlı böcek türleri arasında Lepidoptera takımına bağlı türler önemli bir yeri tutmaktadır. Özellikle larvalarının beslenmesi sonucunda artım kayıplarına neden olmakta, ağaçları zayıf düşürerek sekonder karakterli zararlılara zemin oluşturabilmektedir. Ülkemiz kayın ormanlarında ekonomik zarara yada epidemiye yol açan zararlı türlerle sıklıkla rastlanılmamakla birlikte son yıllarda Bursa-İnegöl ve KütahyaDomaniç sınırında yer alan kayın ormanlarında bir lepidoptera türü olan Calliteara pudibunda (Linneaus, 1758) (Lep.: Erebidae, Lymantriinae) önemli zararlarıyla dikkati çekmektedir. Larvaları kayın yapraklarını yemesi sonucunda ağaçlar tamamen yapraksız kalabilmekte ve artım kaybı meydana gelmektedir. Bu tür esas olarak kayın zararlısı olarak bilinmekle birlikte, yapraklı orman ağacı türlerinde polifag olarak beslenmektedir.

$\mathrm{Bu}$ çalışmada, zararlı tür ile ilgili bilgiler sunulacak ayrıca Bursa-İnegöl ve Kütahya-Domaniç sınırında yer alan kayın e-ISSN: 2148-2683 ormanlarında 2019 yılı sonunda yayılışına ilişkin elde edilen veriler ve mücadelesi için öneriler verilmektedir.

\section{Materyal ve Metot}

2019 yılında yapılan bu çalışmayla kızılkuyruklu kayın tırtılı (Calliteara pudibunda)'nın 2018 ve 2019 y1lında önemli zarara neden olduğu ve Bursa Orman Bölge Müdürlügü İnegöl Orman İşletme Müdürlügüu, Tahtaköprü Orman İşletme Şefliği ile Kütahya Orman Bölge Müdürlügü Domaniç Orman İşletme Müdürlüğü Domaniç Orman İşletme Şefliği sınırları içerisinde yer alan kayın sahalarında inceleme ve araştırmalarda bulunulmuştur. Böceğin morfolojisi ve zarar şekli ile gözlemler gerçekleştirilmiş, insansız hava araçlarından dronlara entegre edilen RGM mono kameralar ile zararlının larvalarının etkili olduğu alanlar ve böceğin ilerleme yönü tespit edilmiştir. Bu amaçla, 30 günlük periyotlarla Dronlara monte edilen kameralar ile izleme faaliyeti gerçekleştirilmiş ve çok bantlı ortofoto harita üretilerek 2019 yılı sonu itibariyle zararın alanı tespit edilmiştir.

\section{Araştırma Sonuçları ve Tartışma}

\subsection{Morfolojik Gözlemler}

Dişi erginleri erkek erginlere göre daha büyük boyutlarda olup, dişi erginler erkeklere göre göre daha açık renktedir. Kanatlar, gri kahverengi renkte olup üzerinde enine şeritler dikkati çekmektedir. Erginlerin kanat açıklığı erkeklerde 3-5 cm; dişi erginlerde ise 4-6 cm arasında değişmektedir (Şekil 1).

Erginlerin birinci çift thorax bacakları istirahat halindeyken öne doğru uzatılmış şekildedir. Bacaklar beyaz ve grimsi tüyler bulunmaktadır.

Dişi erginler yapraklara, gövdeye hatta dallara bırakılan gri renkli yumurtalar (Şekil 2), 2-3.5 mm büyüklüğünde, yuvarlak ve ortalarında belirgin çukurluk bulunmaktadır.

Boyları 3.5-5 cm arasında değişen olgun tırtılları çoğunlukla sarımsı yeşil renkte olup, üzerlerinde sarımtırak tüyler bulunmaktadır. Vücudunda lateralde siyah renkli çizgiler mevcuttur (Şekil 3). Abdomende 11.segmentten uzanan kırmızımtırak renkli kıl demeti larvaların tanınmasında en önemli özelliklerdendir.

Tırtılları ölü örtüde, bir koza içerisinde pupa olmaktadır. Pupaların boyu 2-3.5 cm, enleri ise 1-1.6 cm arasında değişmektedir. Pupalaşma ilk başlarda koyu yeşil yada açık kahverenginde iken ilerleyen süreçte koyu kahverengi bir hal almaktadır (Şekil 4). 

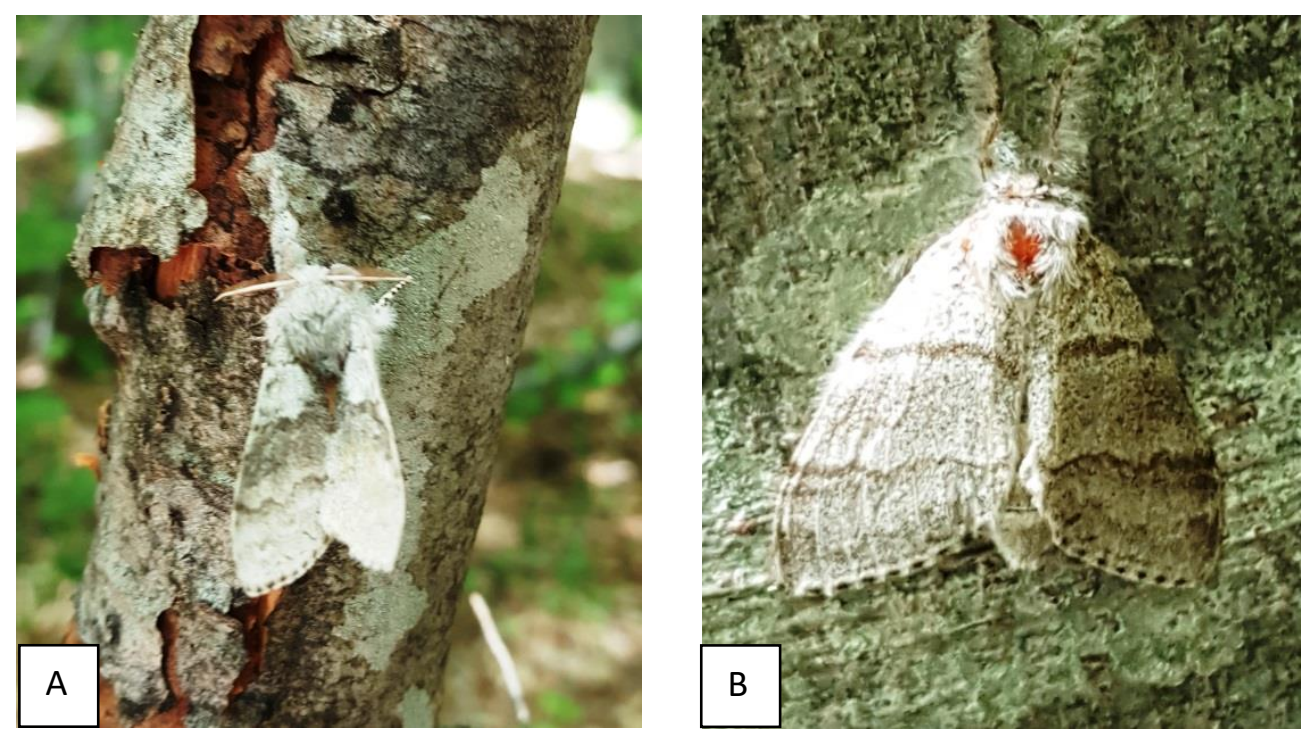

Şekil 1. Calliteara pudibunda erginleri (A: Erkek, B: Dişi )

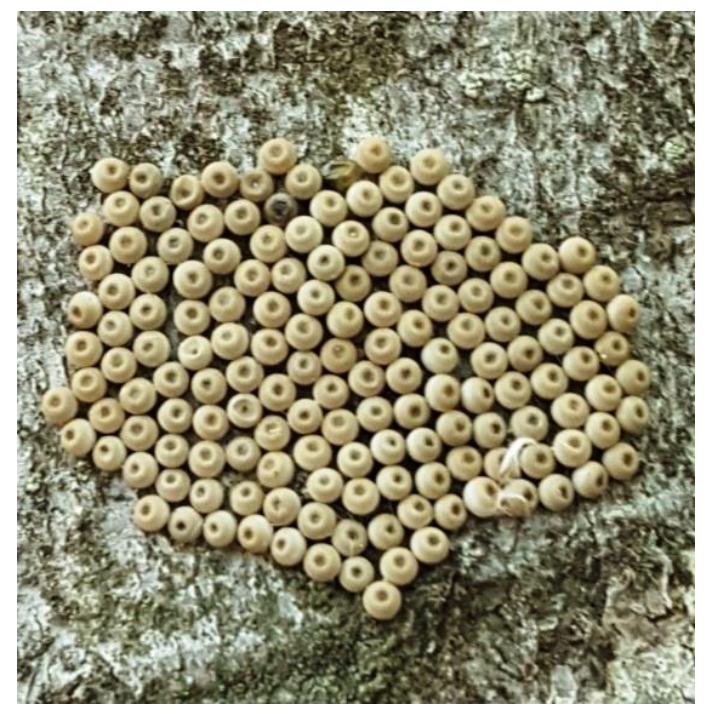

Şekil 2. Calliteara pudibunda yumurta paketi

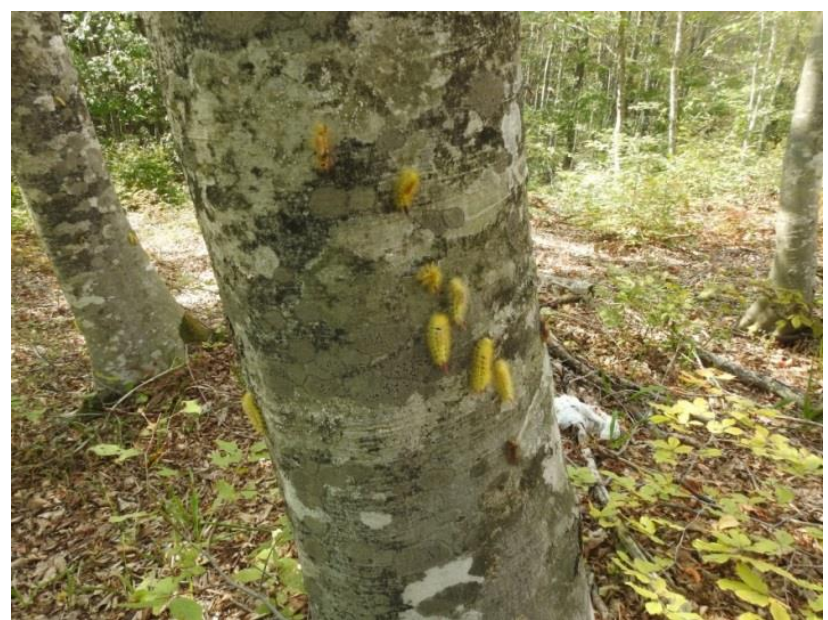

Şekil 3. Calliteara pudibunda olgun larvaları

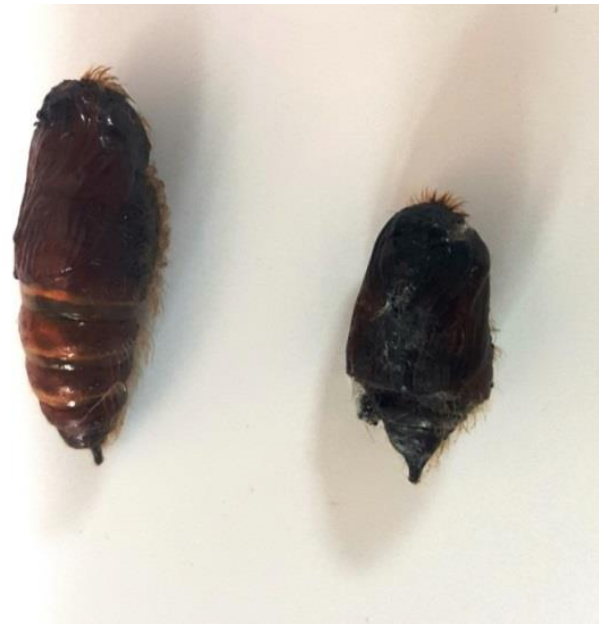

Şekil 4. Calliteara pudibunda pupaları 


\subsection{Konukçu Bitkileri ve Yayılışı}

Türkiye'de daha önce Göktürk ve Aksu (2005) tarafindan Artvin yöresinde kızılağaç ve huş ağaçları üzerinde zararı bildirilen Calliteara pudibunda (Linneaus, 1758), 2018 ve 2019 yıllarında İnegöl (Bursa) kayın ormanlarında epidemi yaparak önemli zarara yol açmıştır. Avrupa'da esas olarak kayın zararlısı olarak bilinmekle beraber, Quercus Salix, Fagus, Betula, Fraxinus, Carpinus, Tilia, Prunus, Crataegus, Juglans, Acer, Castanea, Alnus ve Populus gibi diğer yapraklı türlerde de zararlı olabilmektedir (Peter, 1986; Göktürk ve Aksu, 2005; Mazzaglio ve ark., 2005; Janben, 1998; Urban, 1994). Larvalarının kayın yapraklarını yemesi sonucunda ağaçlar tamamen yapraksız kalabilmekte ve artım kaybı meydana gelmektedir (Şekil 5).

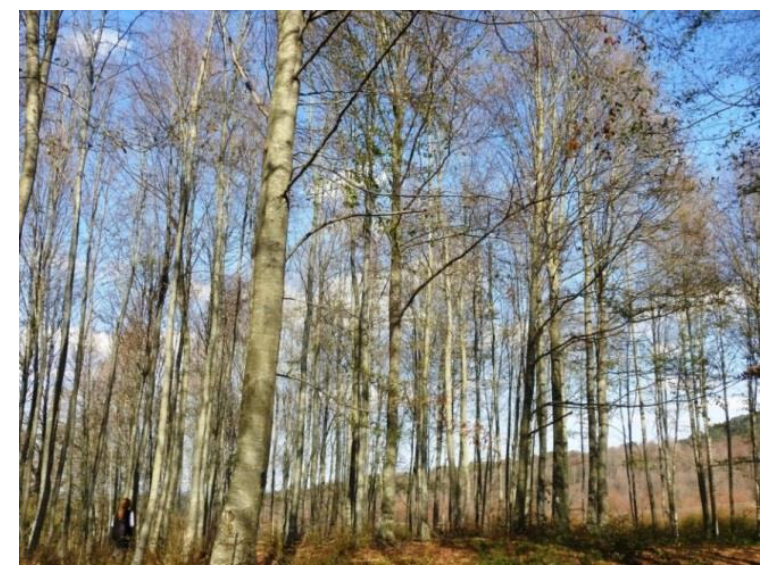

Şekil 5. Calliteara pudibunda tırtılları tarafından zarara uğrayan ağaçlar

Calliteara pudibunda'nın Avrupa'da 37. ve 60. Enlem dereceleri arasında yayılış yaptığı ancak; 48.- 57. Enlemlerde epidemilere yol açtığı bildirilmektedir (Wellenstein, 1978; Klimitzek, 1972; Mazzoglio, 2005; Heqvist, 1949; Nilsson, 1978).

\section{3. İnegöl ve Domaniç Kayın Sahalarında Zararın Yayılışına İlişkin Kayıtlar}

2019 yılında zarar periyodu boyunca, İnsansız Hava Araçları (drone; RGB mono kameralı) ile haritalama için uçuşlar yapılmış ve yüksek çözünürlüklü ortofoto haritalar üretilerek zarar değişimi izlenmiştir. Zarara uğrayan alanın ortofoto haritaları üzerinden sahada genel durum tespit edilmiştir. Sahada, böceğin 2019 yılında zarara neden olduğu alan 453,80 hektar olarak ölçülmüştür (Şekil 6, Şekil 7).

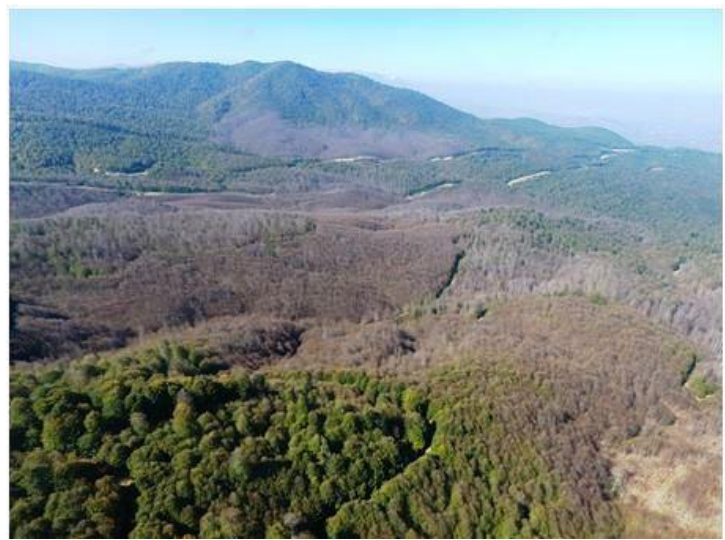

Şekil 6. Zarara uğrayan sahasının dron ile alınan görüntüsü
Bu alanın 339 hektarlık bölümünde, yapraklarla beslenen tırtılların ağaçlarda yaprak bırakmayacak şekilde beslendiği, 114 hektarlık alanda ise zararın daha az yoğunlukta olduğu belirlenmiştir.

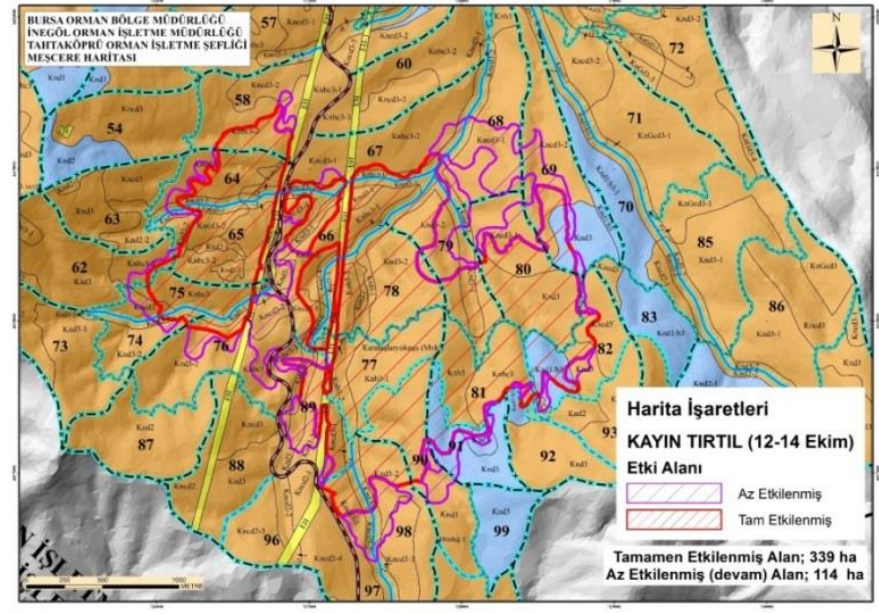

Şekil 7. Kayın Tırtıl zararının 2019 yılı Ekim ayındaki durumu (Meşcere haritası)

Yükselti basamakları göz önünde bulundurulduğunda, kayın sahasının genelinde zararın görüldüğü, ancak daha yoğun zararın 1100-1300 m yükselti basamağında gerçekleştiği tespit edilmiştir (Şekil 8).

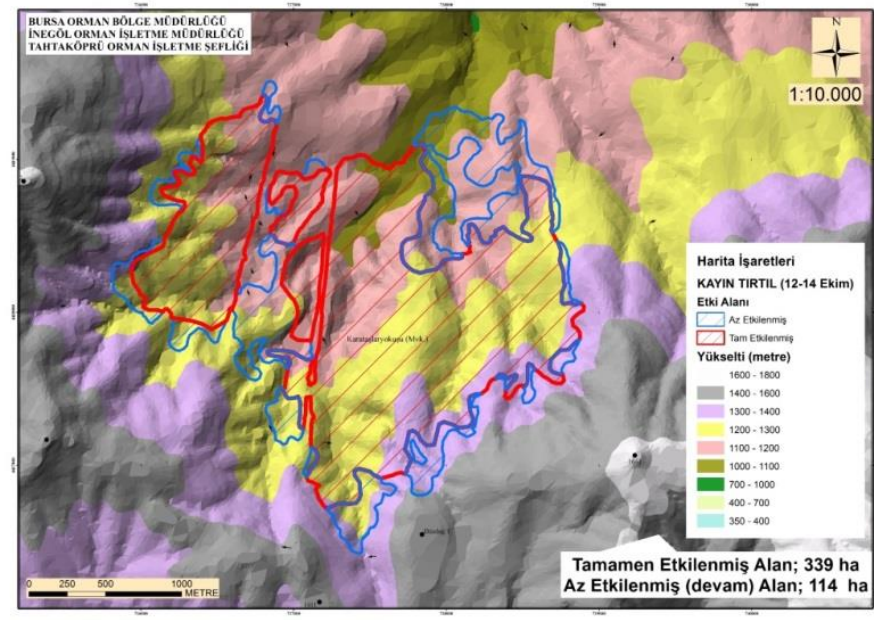

Şekil 8. Arazideki böcek zararının yükselti kuşaklarına göre dağılımı

\section{Sonuç}

Calliteara pudibunda'nın günümüz ve gelecekteki potansiyel alanlarının giderek daha da artış gösterebileceği tahmin edilmektedir. Zararlının mücadelesinde mekanik ve biyolojik savaşın bir arada tercih edileceği entegre savaş yöntemlerinin tercih edilmesi önemlidir.

$\mathrm{Bu}$ kapsamda, sonbaharda pupa periyoduna geçtikten sonra pupaları toplanmak suretiyle mekanik mücadelesi yapılarak popülasyon düzeyi aşağıya çekilmelidir.

Böceğin yumurtalarını bıraktığı dönemde bu yumurtaların bir firça ya da spatula yardımıyla zedelenmesi mekanik mücadelenin bir diğer ayağı olacaktır. 
Sahada böceğin 2018 ve 2019 yıllarında önemli zarara yol açtığı ve popülasyonun epidemi seviyesinde olduğu göz önünde bulundurulduğunda erken larva döneminde Haziran ve Temmuz aylarında larvalara karşı biyolojik mücadele ajanı olan Bacillius thuringiensis var. kurstaki bakterisinin kullanılması tavsiye edilmektedir. Ancak, popülasyonun yüksek olmadığı yıllarda bu bakterinin diğer organizmalara, özellikle de böceğin doğal düşmanı olan türlere zararı olabileceği düşünülerek kullanımından kaçınılmalıdır.

Calliteara pudibunda'nın doğal düşmanı konumunda bulunan parazitoit ve predatör böcek türlerinin belirlenmesi, uzun vadede biyolojik mücadeleye esas olacak şekilde doğal dengenin tekrar kurulması adına büyük önem taşımaktadır. Bunun için, zararlının yumurta ve larva-pupa parazitoitlerinin tespit edilmesi ve bunlardan ümitvar olan türlerin laboratuvarda kitle üretiminin imkânlarının ortaya konulması oldukça önemlidir.

Doğal düşman türlerden sadece böcek türlerinin değil, zararlının larvalarıyla beslenen böcekçil kuş ve memeli hayvanların tespit edilerek, sahada popülasyonunun artırılması biyolojik mücadelenin bir diğer uygulaması olması adına önemlidir.

Zararlının parazitoitlerinin popülasyonun artırılması amacıyla yetişme alanına uygun çiçekli bitkilerin araştırılarak dikim veya tohum ekimi ile sahaya bu çiçekli bitkilerin getirilmesi için gerekli çalışmaların başlatılması, tohum ve fidanların yahut çeliklerin temin edilmesi ve ekim ya da dikim zamanında sahaya uygulamanın yapılması doğal düşmanların sahadaki performansının artırılması adına önerilmektedir.

\section{Kaynakça}

Akyol A., Sarıkaya O. (2017). Situation and Evaluation of Biological and Chemical Control Applications for Forest in Turkey. Applied Ecology and Environmental Research, 15: 341353.

Akyol A., Tolunay A. (2014). Sürdürülebilir Orman Yönetimi Ölçüt ve Göstergelerinin Türkiye İçin Modellenmesi. SDÜ Orman Fakültesi Dergisi, 15: 2132.

Göktürk T, Aksu Y. (2005). Artvin İli Ormanlık Alanlarında Tespit Edilen Calliteara pudibunda (Linneaus, 1758)'nın (Lepidoptera; Lymantriidae) Morfolojisi, Biyolojisi ve Beslenme Özellikleri Üzerine Bir Araştırma. Orman Mühendisliği, Y1l:43, Say1:Temmuz-Ağustos-Eylül, 34-35.

Heqvist K.J. (1949). Om bokspinnarens (Dasychira pudibunda L.) uppträdande i Halland år 1946.- Svenska Skogsvårdsföreningens Tidskrift, 4: 219-227.

IPCC (2014). Impacts, Adaptation and Vulnerability: Summary for Policymakers. Cambridge University Press, Cambridge, United Kingdom and New York.

Janben, J.H. (1998). Freilandstudienm über den Buchenrotschwanz (Dasychira pudibunda L.) im Forstamt Podanin bei Budzyn unter Berücksichtigung einer dortigen Gradation in den Jahren 1992-1994

Klimitzek, D. (1972). Das Vorkommen des Buchenrotschwanzes (Dasychira pudibunda L.) in der Pfalz.- Allgemeine Forstund Jagd-Zeitung, 143 (9): 192-195.

Konukçu, M. (2001). Ormanlar Ve Ormancılığımız: Faydaları, İstatistiki Gerçekler, Anayasa, Kalkınma Planları, Hükümet Programları ve Yıllık Programlarda Ormancılık. Devlet Planlama Teşkilatı Yayınları, Ankara.
Mazzoglio, P.J., Paoletta. M., Patetta. A., Currado, I. (2005). Calliteara pudibunda (Lepidoptera Lymentriidae) in Northwest Italy. Bulletin of Insectology, 58(1): 25-34.

Nilsson, I. (1978). The influence of Dasychira pudibunda (Lepidoptera) on plant nutrient transports and tree growth in a beech Fagus sylvatica forest in southern Sweden.- Oikos, 30: 133-148.

Pearce, W.D., Pearce, G.T.C. (2001). The Value of Foret Ecosystems. A Report to the Secretariat Convention on Biological Diversity

Peter, M. (1986). An outbreak of Dasychira pudibunda L. (Lep., Lymantriidae). Entomologische Nachrichten und Berichte, 30(3): 125-16.

Sarıkaya O, Karaceylan I.B., Şen İ. (2018). Maximum Entropy Modeling (Maxent) of current and future distributions of Ips mannsfeldi (Wachtl, 1879) (Curculionidae: Scolytinae) in Turkey. Appl Ecol Environ Res 16:2527-2535

Urban, J. (1994). Biology of the red tail moth (Calliteara pudibunda L.): Part I. Moths, their occurrence and egg laying. Lesnictvi Prague 40 (7-8): 284-297.

Wellenstein, G. (1978). Lymantriidae, Traegspinner, pp. 316334. In: Die Forstschaedlinge Europas. 3. Schmetterlinge SCHWENKE W., Ed.).- Verlag P. Parey, Berlin und Hamburg. 